\title{
Recipient C7 rs9292795 genotype and the risk of hepatocellular carcinoma recurrence after orthotopic liver transplantation in a Han Chinese population
}

Zhongyi Jiang $^{1 \dagger}$, Qianwei Jiang ${ }^{1 \dagger}$, Xu Fang $^{1 \dagger}$, Pusen Wang ${ }^{1}$, Weitao Que ${ }^{1}$, Hao Li ${ }^{1}$, Yang Yu ${ }^{1}$, Xueni Liu ${ }^{1}$, Chunguang Wang ${ }^{2^{*}}$ and Lin Zhong ${ }^{1 *}$

\begin{abstract}
Background: Complement component(C7) gene has been shown to influence the prognosis in Hepatocellular carcinoma (HCC) patients. The association between C7 and HCC recurrence after orthotopic liver transplantation (OLT), however, is still unknown. The purpose of this study was to evaluate whether the donor and recipient C7 gene polymorphisms are related to HCC recurrence after OLT in the Han Chinese population.

Methods: A total of 73 consecutive patients with HCC who had undergone OLT, both donors and recipients, were involved in this research. A single nucleotide polymorphism of C7, rs9292795, was genotyped using Sequenom MassARRAY in the cohort. The expression of $\mathrm{C7}$ and the association between $\mathrm{C7}$ gene polymorphisms and HCC recurrence following OLT were analyzed by bioinformatics and statistical analysis, respectively.

Results: As shown in database, the expression of C7 was higher in HCC tissues than that in normal tissues, and represented a worse prognosis. We also found that recipient C7 rs9292795 polymorphism, rather than the donor, was significantly associated with HCC recurrence after OLT. Multivariate logistic regression analysis confirmed that TNM stage $(P=0.001)$, Milan criteria $(P=0.000)$ and recipient rs9292795 genotype ( $T$ vs AA/AT, $P=0.008$ ) were independent risk factors for HCC recurrence. Furthermore, the recipient carrying AA/AT showed higher recurrencefree survival (RFS) and overall survival (OS) than that carrying $\Pi(P<0.05)$. In Cox proportional hazards model, TNM stage, recipient rs9292795 genotype, and Milan criteria were identified as independent factors for RFS and OS ( $P<$ 0.05) as well as pre-OLT serum alpha fetoprotein (AFP) level was associated with OS $(P<0.05)$.
\end{abstract}

Conclusions: Recipient C7 rs9292795 gene polymorphism is related to the recurrence of HCC after OLT, which may be a helpful prognostic marker for HCC patients who receive OLT.

Keywords: C7 polymorphism, Hepatocellular carcinoma recurrence, Orthotopic liver transplantation, Prognosis

\footnotetext{
*Correspondence: cgwang1989@163.com; zhongl_3284@hotmail.com

${ }^{\dagger}$ Zhongyi Jiang, Qianwei Jiang and Xu Fang contributed equally to this work.

2Emergency \& Critical Care Department, Shanghai General Hospital, Shanghai

Jiao Tong University School of Medicine, 650 New Songjiang Road,

Songjiang District, Shanghai, China

${ }^{1}$ Department of General Surgery, Shanghai General Hospital, Shanghai Jiao

Tong University School of Medicine, 100 Haining Road, Shanghai 200080,

China
}

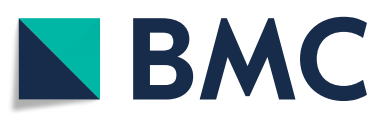

(๑) The Author(s). 2021 Open Access This article is licensed under a Creative Commons Attribution 4.0 International License, which permits use, sharing, adaptation, distribution and reproduction in any medium or format, as long as you give appropriate credit to the original author(s) and the source, provide a link to the Creative Commons licence, and indicate if changes were made. The images or other third party material in this article are included in the article's Creative Commons licence, unless indicated otherwise in a credit line to the material. If material is not included in the article's Creative Commons licence and your intended use is not permitted by statutory regulation or exceeds the permitted use, you will need to obtain permission directly from the copyright holder. To view a copy of this licence, visit http://creativecommons.org/licenses/by/4.0/ The Creative Commons Public Domain Dedication waiver (http://creativecommons.org/publicdomain/zero/1.0/) applies to the data made available in this article, unless otherwise stated in a credit line to the data. 


\section{Introduction}

Hepatocellular carcinoma (HCC), the most frequent primary liver malignancy (85-90\%), is the fifth most commonly diagnosed malignancy and the third leading cause of cancer-related deaths in the world over the past two decades [1]. It is estimated that there are approximately $841,000 \mathrm{HCC}$ cases and 782,000 HCC-related deaths throughout the world in 2018 [1]. Most of the new cases of HCC occur in developing countries, and 55\% of new cases worldwide occurred in China, which is related to the epidemic of hepatitis B virus (HBV) $[2,3]$. Orthotopic liver transplantation (OLT) is considered as the most effective treatment and a routine practice for patients with HCC [4]. Owing to improved surgical techniques and new immunosuppressive drugs, OLT offers optimal outcomes by removing and replacing the entire tumorbearing liver, and the recipient long-term survival has increased steadily, with a current 5-year survival exceeding $75 \%$ [5]. Most transplant centers have adopted the Milan, University of California San Francisco guidelines to select the best criteria for transplantation and improve the survival time after OLT [6-8] as their official tool. However, the efficacy of patients with HCC following OLT depends on the risk of the recurrence and it remains a significant challenge. In the first 3 year after OLT, the recurrence rate of patients with $\mathrm{HCC}$ was $8-$ $15 \%$ [9].

Although the recent research reports illuminate signaling regulators related to early HCC recurrence [10-12], the underlyingly overall mechanism of HCC recurrence after OLT remains largely unknown. The tumor size, number, histological grade of differentiation, microvascular and macrovascular invasion, alpha-fetoprotein level, and ischemia time are proved as the predictors of HCC recurrence after OLT [8, 13-15]. However, it is more critical to explore the genetic mechanism of $\mathrm{HCC}$ recurrence after OLT. A previous study demonstrated that the single-nucleotide polymorphisms (SNPs) of telomere maintenance gene play a potential role in the survival of HCC patients [16]. A great many of SNPs are functional and may resulting in recurrence of $\mathrm{HCC}$ by altering gene expression or protein function $[17,18]$.

The Complement component 7(C7) gene, located on chromosome 5p13.1, is a terminal component of the complement cascade. C7 encodes a serum glycoprotein together with complement components C5b, C6, C8, and $\mathrm{C} 9$, which form a membrane attack complex (MAC) as part of the terminal complement pathway of the innate immune system $[19,20]$. The complement system serves as the innate immune system, which is important in immune surveillance and homeostasis [21]. It has been previously reported that $\mathrm{C} 7$ deficiency leads to increased susceptibility to a number of human diseases $[19,20,22,23]$. Besides, recent studies also confirmed that complement system associated with the development of carcinomas [24, 25].

The OLT patients have both donor and recipient two genetic profiles, which both may be underlying causes of HCC recurrence following OLT. A previous study demonstrated the association of C7 polymorphisms with infection after OLT [26]. We therefore aim to verify whether donor or recipient $\mathrm{C} 7$ polymorphisms are associated with the risk of $\mathrm{HCC}$ recurrence after OLT, which might be an effectively prognostic marker of HCC patient survival after OLT in a Han Chinese population.

\section{Materials and methods \\ Patients}

A total of 224 adult patients, who had undergone orthotopic liver transplantation for malignant liver disease and other reasons of hepatic failure between June 2006 and December 2013 at the Shanghai General Hospital, Shanghai Jiao Tong University, School of Medicine, were enrolled. The patients with benign liver function failure (alcohol and autoimmune hepatitis) were excluded. The inclusion criteria of these transplantation patients were as follows: aging 18 or older, compatible blood and tissue type with donors and no multiorgan combined transplantation. All the patients were Han Chinese. Thus, only 73 patients with HCC were included in the study. All patients were treated using immunosuppression regimen after OLT, which comprised cyclosporine or tacrolimus (FK506), mycophenolate, and prednisone. Patients positive for HBV-DNA were treated with Entecavir before OLT and hepatitis B immune globulin 800 IU fixed dosing during and after the operation. After leaving the hospital, all patients were monitored for tumor recurrence or metastasis using the AFP test, ultrasonography, and emission computed tomography every 3 months.

\section{Ethics statement}

The consent for participating in this study was received from each donor and recipient. Every organ donation or transplantation was approved by the Institutional Review Board Liver Transplantation Surgery of the Shanghai General Hospital, Shanghai Jiao Tong University, School of Medicine, China, and carried out strictly in accordance with the guidelines of the Ethics Committee of the hospital, current law of the Chinese Government, and the Declaration of Helsinki [27]. No organs/tissues were procured from prisoners.

\section{DNA extraction and genotyping}

Genomic DNA was obtained from the donor and recipient liver specimens using an AllPrep DNA/RNA Mini kit (Qiagen, Venlos, the Netherlands) following the manufacturer's protocol. All the tissues were previously 
stored at $-80^{\circ} \mathrm{C}$ before use. Single-nucleotide polymorphism (SNP) genotyping was performed using a Sequenom MassARRAY SNP genotyping platform (Sequenom, CA, USA).

\section{Gene expression analyses}

The expression of $\mathrm{C} 7$ in liver hepatocellular carcinoma (LIHC) tissue and normal tissue as well as the effect of C7 expression level on LIHC patient survival were analyzed using UALCAN database [28].

\section{Statistical analysis}

The OLT recipients were divided into two groups: HCC recurrence cases and controls of non-recurrence. Data were analyzed using SPSS ver.19.0 statistical software (SPSS Inc., IL, USA). The Wilcoxon signed-rank test was used to evaluate the descriptive variables which expressed as the median (range) as well as using the Pearson's $\chi 2$ test or Fisher's exact to compare the Categorical variables. The allele and genotype frequencies of C7 polymorphisms, both the donor and recipient, were

Table 1 Demographic, clinical and pathological characteristics of the two groups of the HCC patients

\begin{tabular}{|c|c|c|c|}
\hline Parameter & $\begin{array}{l}\text { Recurrence group } \\
(n=29)\end{array}$ & $\begin{array}{l}\text { Non-recurrence group } \\
(n=44)\end{array}$ & $P$ value \\
\hline Recipient age & $48(21-67)$ & $49.5(33-62)$ & 0.811 \\
\hline$\geq 50$ & $13(44.8 \%)$ & $22(50.0 \%)$ & \\
\hline$<50$ & 16(55.2\%) & $22(50.0 \%)$ & \\
\hline Recipient gender & & & 1.000 \\
\hline Male & $25(86.2 \%)$ & $39(88.6 \%)$ & \\
\hline female & $4(13.8 \%)$ & $5(11.4 \%)$ & \\
\hline Hepatitis B & & & 0.207 \\
\hline Yes & $25(86.2) \%)$ & $42(95.5 \%)$ & \\
\hline No & $4(13.8 \%)$ & $2(4.5 \%)$ & \\
\hline Cirrhosis & & & 0.154 \\
\hline Yes & $20(69.0 \%)$ & $37(84.1 \%)$ & \\
\hline No & $9(31.0 \%)$ & $7(15.9 \%)$ & \\
\hline Milan criteria & & & 0.000 \\
\hline $\ln$ & $2(6.9 \%)$ & $29(65.9 \%)$ & \\
\hline Out & 27(93.1\%) & $15(34.1 \%)$ & \\
\hline TNM stage & & & 0.000 \\
\hline $1-2$ & $12(41.4 \%)$ & $38(86.4 \%)$ & \\
\hline $3-4$ & $17(58.6 \%)$ & $6(13.6 \%)$ & \\
\hline Tumor size $(\mathrm{cm})$ & & & 0.000 \\
\hline$>5$ & $26(89.7 \%)$ & $18(40.9 \%)$ & \\
\hline$\leq 5$ & $3(10.3 \%)$ & $26(59.1 \%)$ & \\
\hline Multinodular type & & & 0.219 \\
\hline YES & $15(51.7 \%)$ & $30(68.2 \%)$ & \\
\hline NO & $14(48.3 \%)$ & $14(31.8 \%)$ & \\
\hline Pre-OLT serum AFP level & & & 0.165 \\
\hline$\leq 400(\mathrm{ng} / \mathrm{ml})$ & $19(65.5 \%)$ & $36(81.8 \%)$ & \\
\hline$>400(\mathrm{ng} / \mathrm{ml})$ & $10(34.5 \%)$ & $8(18.2 \%)$ & \\
\hline Microvascular invasion & & & 0.000 \\
\hline Yes & $14(48.3 \%)$ & $2(4.5 \%)$ & \\
\hline No & $15(51.7 \%)$ & $42(95.5 \%)$ & \\
\hline Macrovascular invasion & & & 0.425 \\
\hline YES & $4(57.1 \%)$ & $3(42.9 \%)$ & \\
\hline NO & $25(37.9 \%)$ & $41(62.1 \%)$ & \\
\hline
\end{tabular}

Abbreviations

HCC hepatocellular carcinoma, TNM tumor node metastasis, AFP alpha-fetoprotein, OLT orthotopic liver transplantation 
Table 2 Recipient and donor C7 genotype distribution and the association with HCC recurrence

\begin{tabular}{|c|c|c|c|c|}
\hline & \multicolumn{2}{|c|}{ Genotype distribution, n (\%) } & \multirow[t]{2}{*}{$P$ value } & \multirow[t]{2}{*}{ HWE $P$ value } \\
\hline & Recurrence $(n=29)$ & Non-recurrence $(n=44)$ & & \\
\hline \multicolumn{5}{|c|}{ Recipient rs9292795 } \\
\hline AA & $1(3.4 \%)$ & $8(18.2 \%)$ & & \\
\hline AT & $8(27.6 \%)$ & $20(45.5 \%)$ & 0.016 & 0.858 \\
\hline$\pi$ & $20(69.0 \%)$ & $16(36.4 \%)$ & & \\
\hline \multicolumn{5}{|c|}{ Recessive model } \\
\hline AA & $1(3.4 \%)$ & $8(18.2)$ & & \\
\hline $\mathrm{AT} / \mathrm{TT}$ & 28(96.6\%) & $36(81.8 \%)$ & 0.078 & \\
\hline \multicolumn{5}{|c|}{ Dominant model } \\
\hline$\pi$ & $20(69.0 \%)$ & $16(36.4 \%)$ & 0.009 & \\
\hline AA/AT & $9(31.0 \%)$ & $28(63.6 \%)$ & & \\
\hline \multicolumn{5}{|c|}{ Additive model } \\
\hline AT & $8(27.6 \%)$ & $20(45.5 \%)$ & & \\
\hline $\mathrm{AA} / \mathrm{TT}$ & 21 & 24 & 0.146 & \\
\hline \multicolumn{5}{|c|}{ Donor rs9292795 } \\
\hline AA & $3(10.3 \%)$ & $4(9.1 \%)$ & & \\
\hline AT & $16(55.2 \%)$ & $23(52.3 \%)$ & & \\
\hline$\pi$ & $10(34.5 \%)$ & $17(38.6 \%)$ & 0.933 & 0.355 \\
\hline \multicolumn{5}{|c|}{ Recessive model } \\
\hline AA & $3(10.3 \%)$ & $4(9.1 \%)$ & & \\
\hline $\mathrm{AT} / \mathrm{TT}$ & 26(89.7\%) & 40(90.9\%) & 1.000 & \\
\hline \multicolumn{5}{|c|}{ Dominant model } \\
\hline$\pi$ & $10(34.5 \%)$ & $17(38.6 \%)$ & & \\
\hline AA/AT & $19(65.5 \%)$ & $27(61.4 \%)$ & 0.087 & \\
\hline \multicolumn{5}{|c|}{ Additive model } \\
\hline AT & $16(55.2 \%)$ & 23(52.3\%) & & \\
\hline $\mathrm{AA} / \mathrm{TT}$ & 13(44.8\%) & $21(47.7 \%)$ & 1.000 & \\
\hline
\end{tabular}

Abbreviations: HCC hepatocellular carcinoma, HWE Hardy-Weinberg equilibrium

calculated through SHEsis Online Version (http:// analysis.bio-x.cn/myAnalysis.php) and Hardy-Weinberg equilibrium test [29]. Odds ratio and 95\% confidence interval $(\mathrm{CI})$ were tested using the logistic regression analysis. Kaplan-Meier survival curve analysis was performed to estimate the Recurrence-free survival (RFS) and overall survival (OS) and then adjusted by log-rank test. The independent factors associating with RFS and OS were further investigated by the multivariate Cox's proportional hazards model following the univariate analysis. The $P$ value $<0.05$ was considered statistically significant.

\section{Results}

The basic and clinical characteristics of OLT patients

This study consisted of $73 \mathrm{HCC}$ patients who had undergone OLT including 64 males and 9 females, with a median age of 49 years (aged 21-67 years). All of the patients were divided into two groups, recurrence $(n=$ 29 ) and non-recurrence $(n=44)$. The follow-up time

Table 3 Multivariate logistic regression analysis of risk factors associated with HCC recurrence

\begin{tabular}{lll}
\hline Factors & Odds ratio $(\mathbf{9 5} \% \mathbf{C l})$ & $P$ value \\
\hline TNM stage $(0=$ stage $1-2,1=$ stage $3-4)$ & $8.302[1.723-40.008]$ & 0.001 \\
Milan criteria(1= out, $0=$ in) & $26.100[5.453-124.921]$ & 0.000 \\
Recipient rs9292795 $(1=$ AA/AT,2 $=\pi$ T) & $3.889[1.433-10.551]$ & 0.008
\end{tabular}




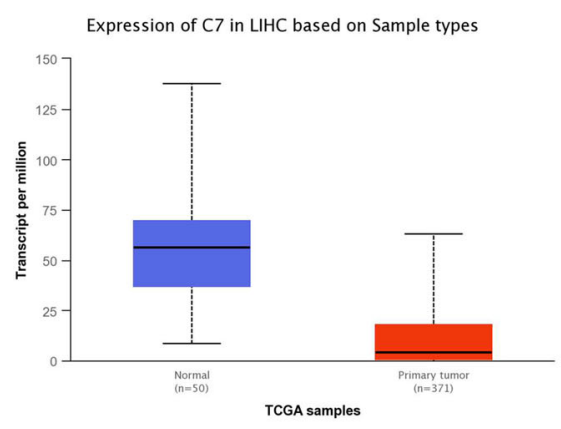

(a)

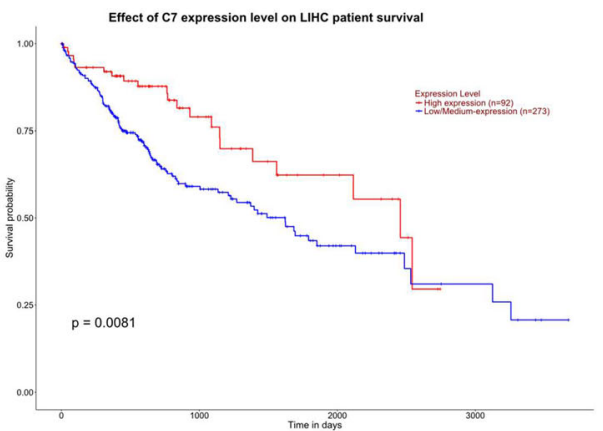

(b)

Fig. 1 Expression of C7 in human tissue database. a Expression of C7 gene is lower in LIHC primary tumor $(n=371)$ than in normal tissue $(n=50)$. b Kaplan-Meier analysis of overall survival (OS) grouped by high C7 and low C7 levels

ranged from 2.7 to 72 months. The mean follow-up period was 30.6 months. Moreover, 57 patients had the etiology of liver cirrhosis. As we found that the Milan criteria, TNM stage, tumor size, and microvascular invasion were statistically significant $(P<0.05)$. The patient demographic, and clinical and pathological characteristics are listed in Table 1.

\section{C7 rs9292795 genotype distribution and its association with the HCC recurrence after OLT}

As shown in Table 2, the distribution of $\mathrm{C} 7$ genotypes is presented. We tested whether all genotype frequencies satisfy the Hardy-Weinberg equilibrium. There was no statistically significant in the frequencies of distribution of $\mathrm{C} 7$ genotype polymorphism of donor between recurrence group and non-recurrence group. On the contrary, the difference is quite significant in the recipient group. In addition, we also observed that the dominant model was the most significant, and the recurrence rate was notably higher in patients with the recipient rs9292795 TT genotype than in those with AA/AT genotype (69\% vs $31 \%, P=0.009$ ).

\section{Risk factors for recurrence: multivariate logistic regression analysis}

The potential risk factors for HCC recurrence after OLT, testing by the Pearson's $\chi^{2}$ test or Fisher's exact test $(P<0.05)$, are presented in Table 1 . Clinical parameters such as Milan criteria, TNM stage, tumor size, multinodular type, microvascular invasion, and macrovascular invasion were involved. On account of TNM staging including the size of tumor, the variable tumor size was excluded to avoid collinearity. Finally, genetic factors (TT vs. AA/AT) were selected in the model in which the results could be more credible. Collinearity diagnostics testing had shown no collinearity (tolerance $>0.1$ ) of all these variables. According to their clinical significance, we defined appropriate cutoff levels.
Multivariate logistic analysis indicated that HCC recurrence after OLT significantly associated with the following factors: TNM stage $[\mathrm{OR}=8.302(1.723-40.008), P=$ 0.001 ], Milan criteria [OR $=26.100(5.453-124.921), P=$ 0.000 ], and recipient rs9292795 [TT vs AA/AT, OR $=$ 3.889 (1.433-10.551), $P=0.008$ ] (Table 3).

\section{Database analyses, Univariate cox hazard regression analysis and Kaplan-Meier survival curves to detect risk} factors for recurrence

We further comprehensive analysis TCGA datasets using the UALCAN database objective to validate our findings. As shown in Fig.1a, detection of 371 LIHC tissues and 50 normal tissues demonstrated

Table 4 Prognostic factors associated with RFS and OS in the univariate Cox analysis

\begin{tabular}{|c|c|c|}
\hline Parameter & RFS, $P$-value & OS, $P$-value \\
\hline Recipient age $(<50 / \geq 50)$ & 0.531 & 0.284 \\
\hline Gender (Male/ Female) & 0.831 & 0.891 \\
\hline Hepatitis B (yes/no) & 0.108 & 0.953 \\
\hline Cirrhosis (yes/no) & 0.095 & 0.306 \\
\hline Milan criteria (in/out) & $0.000^{*}$ & $0.000^{*}$ \\
\hline TNM stage(1-2/3-4) & $0.000^{*}$ & $0.000^{*}$ \\
\hline Tumor size $(\mathrm{cm})(\leq 5 />5)$ & $0.000^{*}$ & $0.001^{*}$ \\
\hline Multinodular type (yes/no) & 0.111 & 0.172 \\
\hline Microvascular invasion (yes/no) & $0.000^{*}$ & 0.000 \\
\hline Macrovascular invasion (yes/no) & 0.367 & 0.627 \\
\hline serum AFP level $(\leq 400 />400)$ & 0.060 & $0.003^{*}$ \\
\hline Recipient rs9292795(TT vs AA/AT) & $0.005^{*}$ & $0.037^{*}$ \\
\hline Recipient rs9292795(TT vs AA vs AT) & $0.014^{*}$ & $0.047^{*}$ \\
\hline Donor rs9292795(TT vs AA/AT) & 0.825 & 0.927 \\
\hline Donor rs9292795(TT vs AA vs AT) & 0.972 & 0.996 \\
\hline
\end{tabular}

Abbreviations:

HCC hepatocellular carcinoma, TNM tumor node metastasis, AFP alphafetoprotein, RFS recurrence-free survival, OS overall survival, ${ }^{*} P<0.05$ 


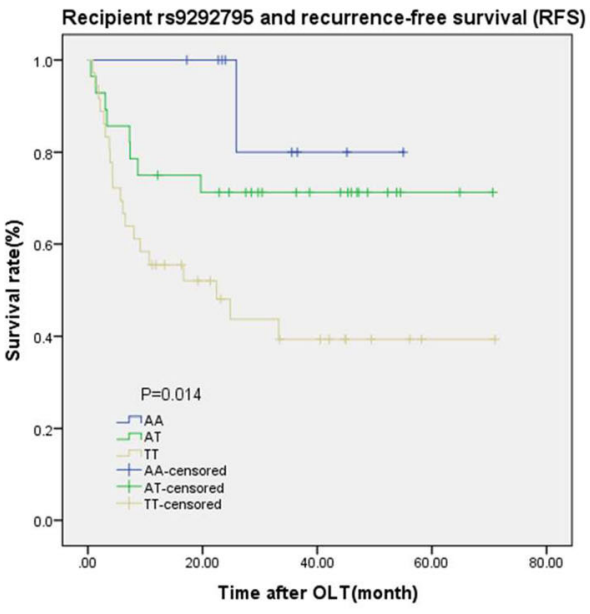

(a)

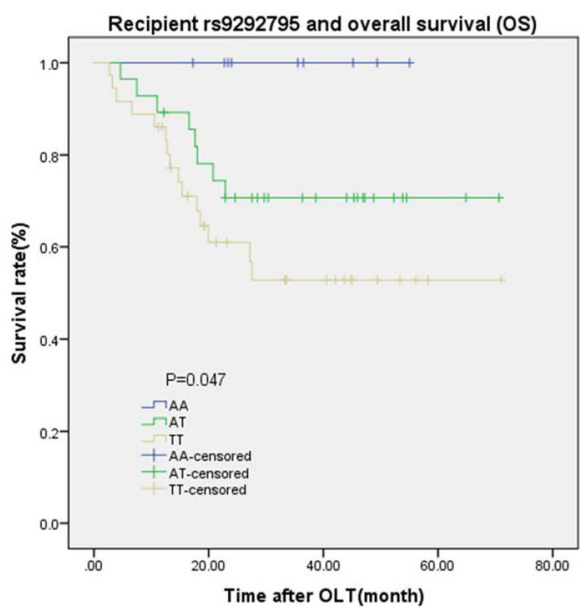

(b)

Fig. 2 Kaplan-Meier survival estimates of a recurrence-free survival (RFS) and $\mathbf{b}$ overall survival (OS) between the different recipient genotypes ( $A A, A T$, and $T$ ) of the recipient

that C7 was lower expression in LIHC tissues. We also found that LIHC patients with low/medium-expression of $\mathrm{C} 7$ had a worse prognosis (Fig.1b). The detailed findings of the univariate Cox regression analysis for each risk factor are listed in Table 4. It is worth nothing that Milan criteria, TNM stage, tumor size, microvascular invasion, pre-OLT serum AFP level, and recipient rs9292795 (TT vs. AA/AT) were considered to be statistically significant factors for both RFS and OS $(P<0.05)$. Besides, RFS and OS were analyzed by the Kaplan-Meier survival estimates and the log-rank test considering the genetic factors. Significant differences were found in recipient C7 RFS and OS among recipients carrying the
AA, AT, and TT alleles $(P=0.014$ and $P=0.047$, respectively; Fig.2a, b). Shown here, we observed that the RFS and OS in the recipient AA/AT group were obviously highly than in the TT group. In contrast, no significant differences were observed when the C7 SNP polymorphisms of the donor were analyzed and their association with the survival after transplantation was assessed (no significant differences in RFS and OS between the donor C7 genotypes; $P=$ 0.972 and $P=0.996$, respectively; Fig. 3a, b).

\section{Multivariate cox regression models}

We further investigated the prognostic factors associating with RFS and OS by the multivariate Cox model.

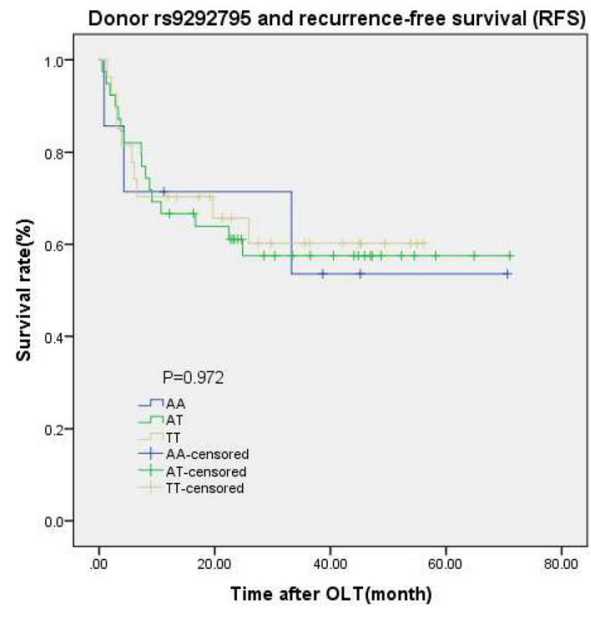

(a)

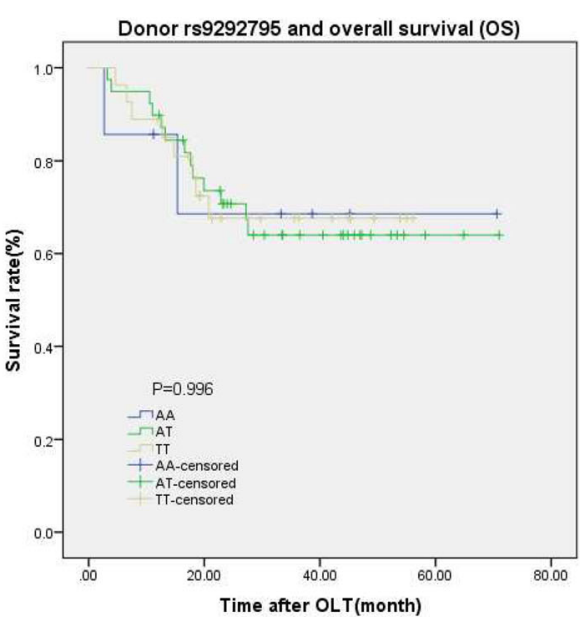

(b)

Fig. 3 Kaplan-Meier survival estimates of a recurrence-free survival (RFS) and $\mathbf{b}$ overall survival (OS) between the different recipient genotype (AA, AT, and TT) of the donor 
The factors with corresponding $P<0.05$ in the univariate analysis were enrolled. Collinearity diagnostics testing performed as we mentioned above. As shown in Table 5, TNM stage $(P<0.001)$, recipient rs9292795 $(P=0.003)$, and Milan criteria $(P=0.000)$ were independent factors for RFS. Furthermore, AFP $(P=0.001)$, TNM stage $(P<$ $0.001)$, recipient rs9292795 $(P=0.001)$, and Milan criteria $(P=0.001)$ were independent factors for OS among patients with HCC who had undergone OLT. Recipient rs9292795 TT type results in shorter OS, RFS, and higher risk for recurrence.

\section{Discussion}

The Complement component 7(C7) located on chromosome fragment 5p13.1-13.3, which might involve in the progression of cancer if the copy number variated [20]. In this study, we investigated the expression of $\mathrm{C} 7$ in HCC tissue as well as the association between $C 7$ gene variations and $\mathrm{HCC}$ recurrence following OLT. Based on the UALCAN database validated that $C 7$ gene was lower expressed in HCC tissues with shorter OS in patients. Obviously, our findings indicated that the recipient polymorphism of C7 rs9292795 had significant association with HCC recurrence after OLT. RFS and OS in the recipients C7 rs9292795 TT type group were remarkably shorter than in the AA/AT group, especially higher HCC recurrence after OLT. The results suggested that recipient C7 rs9292795 might help establish a potentially effective system for prognosis and organ allocation.

The serum glycoprotein that $\mathrm{C} 7$ encodes is one of the central components of membrane attack complex (MAC), which is part of the terminal complement pathway of the innate immune system [20]. A previous study indicates that MAC as the product of complement activation may promote tumor growth [24]. In addition, MAC activating complement pathway plays an important role in the pathogenesis of a variety of liver diseases, such as defend foreign pathogens by lysing them directly [30]. Furthermore, Zhong et al. [26] had demonstrated that the association of $\mathrm{C} 7$ polymorphisms with infection after OLT in a Han Chinese population. Therefore, we hypothesis that the $\mathrm{C} 7$ polymorphisms may associated with the HCC recurrence following OLT.

According to previous reports, the expression of C7 was remarkably reduced in oesophageal carcinoma [19] and non-small cell lung cancer (NSCLC) [20] tissues. Moreover, multivariate cox regression analysis showed low-expressed C7 had a higher risk for recurrence in NSCLC patients [20]. Our results demonstrated that the recipients with the C7 rs9292795 TT genotype had worse survival and higher incidence of HCC recurrence following OLT compared with those carrying the C7 rs9292795 AA/AT genotype. Combined with existing reports, our study suggested that C7 rs9292795 is a functional SNP and may contribute to the HCC recurrence after OLT. However, the mechanisms of how the C7 rs9292795 TT genotype is involved in HCC recurrence following OLT is complicated and need more in-depth research to reveal them.

Similar to the previous study, we found TNM stage and Milan criteria were independent factors for $\mathrm{HCC}$ recurrence after OLT in clinical analysis [14]. Besides, Milan criteria, TNM stage, microvascular invasion, preOLT serum AFP level were independent factors for patient prognosis.

Notably, the present study had some limitations. First, the sample size was relatively small, and the follow-up period was not long enough. Second, most patients had HBV-related liver diseases. Hence, further studies should involve large samples with various HCC causes (hepatitis $\mathrm{C}$ virus, aflatoxin, and alcohol). Third, the relationship between the $\mathrm{C} 7$ gene polymorphism, C7 gene expression, and HCC recurrence after OLT is complicated and hence difficult to uncover. Future studies should focus on gene and protein functions to fully understand C7and the recurrence of liver carcinoma.

In summary, our findings demonstrated that $\mathrm{C} 7$ gene polymorphism obviously associated with HCC

Table 5 Prognostic factors associated with RFS and OS in the multivariate Cox regression analysis

\begin{tabular}{|c|c|c|}
\hline & Hazard ratio $(95 \% \mathrm{Cl})$ & $P$ value \\
\hline \multicolumn{3}{|l|}{ RFS } \\
\hline Milan criteria & 16.408 [3.869-69.592] & 0.000 \\
\hline Recipient rs9292795(1 = TT,2 = AA/AT) & $3.672[1.574-8.566]$ & 0.003 \\
\hline TNM stage $(1=1-2$ stage, $2=3$-4stage $)$ & $5.738[2.305-14.288]$ & 0.000 \\
\hline \multicolumn{3}{|l|}{ OS } \\
\hline AFP & $3.085[1.012-9.408]$ & 0.048 \\
\hline Milan criteria & $11.078[2.587-47.443]$ & 0.001 \\
\hline Recipient rs9292795(1 = T,2 = AA/AT) & $4.415[1.792-10.879]$ & 0.001 \\
\hline TNM stage( 1 = 1-2stage,2 = 3-4stage $)$ & $10.318[3.016-35.294]$ & 0.000 \\
\hline
\end{tabular}

Abbreviations:

Cl confidence interval, TNM tumor node metastasis, AFP alpha-fetoprotein 
recurrence in patients who had undergone OLT. C7 rs9292795 TT genotype of the recipient rather than of the donor is of greater value in predicting the risk of HCC recurrence after OLT. Furthermore, C7 rs9292795 may represented an independent factor for long-term prognosis of patients with HCC following OLT.

\section{Abbreviations}

AFP: serum alpha fetoprotein; C7: Complement component; $\mathrm{Cl}$ : confidence interval; HBV: hepatitis B virus; HCC: Hepatocellular carcinoma; HWE: HardyWeinberg equilibrium; LIHC: liver hepatocellular carcinoma; MAC: membrane attack complex; OLT: orthotopic liver transplantation; OR: odds ratio; OS: overall survival; RFS: recurrence-free survival; SNPs: single nucleotide polymorphisms; TNM: tumor node metastasis

\section{Acknowledgements}

We would like to thank all the patients and individuals in this study for their participation. We are also very grateful for the assistance of the clinicians and for the hospital staff of the Shanghai General Hospital, Shanghai Jiao Tong University, School of Medicine who contributed data for this study.

\section{Authors' contributions}

Zhongyi Jiang, Qianwei Jiang, and Xu Fang collected and analyzed the patient data. Pusen Wang and Xueni Liu searched and analyzed literature. Yang Yu, Hao Li, and Weitao Que. did data interpretation. Lin Zhong and Chunguang Wang proposed the study. Zhongyi Jiang, Qianwei Jiang, and Xu Fang performed the research and wrote the manuscript. All authors contributed to the design and interpretation of the study and to further drafts. The author(s) read and approved the final manuscript.

\section{Funding}

Not applicable.

\section{Availability of data and materials}

Data sharing is not applicable to this article as no datasets were generated during the current study.

\section{Declarations}

\section{Ethics approval and consent to participate}

This study was conducted under the approval of the Institutional Review Boards of Liver Transplantation Surgery of the Shanghai General Hospital, Shanghai Jiao Tong University, School of Medicine, China. All participants were aware of the content of the study and signed an informed consent. No organs/tissues were procured from prisoners.

\section{Consent for publication}

Not applicable.

\section{Competing interests}

The authors declare that they have no competing interests.

Received: 20 December 2020 Accepted: 26 April 2021

Published online: 08 May 2021

\section{References}

1. Bray F, Ferlay J, Soerjomataram I, Siegel RL, Torre LA, Jemal A. Global cancer statistics 2018: GLOBOCAN estimates of incidence and mortality worldwide for 36 cancers in 185 countries. CA Cancer J Clin. 2018;68(6):394-424. https://doi.org/10.3322/caac.21492.

2. Kew MC. Hepatocellular carcinoma in developing countries: Prevention, diagnosis and treatment. World J Hepatol. 2012;4(3):99-104.

3. Chen W, Zheng R, Baade PD, Zhang S, Zeng H, Bray F, et al. Cancer statistics in China, 2015. CA Cancer J Clin. 2016;66(2):115-32.

4. Starzl TE. The long reach of liver transplantation. Nat Med. 2012;18(10):148992. https://doi.org/10.1038/nm.2927.

5. Kwong A, Kim WR, Lake JR, Smith JM, Schladt DP, Skeans MA, et al. OPTN/ SRTR 2018 Annual Data Report: Liver. Am J Transplant. 2020;20(Suppl s1): 193-299.
6. Sapisochin G, Bruix J. Liver transplantation for hepatocellular carcinoma: outcomes and novel surgical approaches. Nat Rev Gastroenterol Hepatol. 2017;14(4):203-17. https://doi.org/10.1038/nrgastro.2016.193.

7. Murray CJL, Barber RM, Foreman KJ, Abbasoglu Ozgoren A, Abd-Allah F, Abera SF, et al. Global, regional, and national disability-adjusted life years (DALYs) for 306 diseases and injuries and healthy life expectancy (HALE) for 188 countries, 1990-2013: quantifying the epidemiological transition. Lancet. 2015;386(10009):2145-91. https://doi.org/10.1016/S0140-6736(15)61340-X.

8. Yao FY, Ferrell L, Bass NM, Watson JJ, Bacchetti P, Venook A, et al. Liver transplantation for hepatocellular carcinoma: expansion of the tumor size limits does not adversely impact survival. Hepatology (Baltimore, Md). 2001; 33(6):1394-403.

9. Feng J, Zhu R, Feng D, Yu L, Zhao D, Wu J, et al. Prediction of early recurrence of solitary hepatocellular carcinoma after Orthotopic liver transplantation. Sci Rep. 2019;9(1):15855. https://doi.org/10.1038/s41598-01952427-8.

10. Wang SM, Ooi LLPJ, Hui KM. Upregulation of Rac GTPase-activating protein 1 is significantly associated with the early recurrence of human hepatocellular carcinoma. Clin Cancer Res. 2011;17(18):6040-51. https://doi. org/10.1158/1078-0432.CCR-11-0557.

11. Chen J, Xia H, Zhang X, Karthik S, Pratap SV, Ooi LL, et al. ECT2 regulates the rho/ERK signalling axis to promote early recurrence in human hepatocellular carcinoma. J Hepatol. 2015;62(6):1287-95. https://doi.org/10.1 016/j.jhep.2015.01.014

12. Chen J, Rajasekaran M, Xia H, Zhang X, Kong SN, Sekar K, et al. The microtubule-associated protein PRC1 promotes early recurrence of hepatocellular carcinoma in association with the Wnt/B-catenin signalling pathway. Gut. 2016;65(9):1522-34. https://doi.org/10.1136/ gutjnl-2015-310625

13. Li WX, Li Z, Gao PJ, Gao J, Zhu JY. Histological differentiation predicts postliver transplantation survival time. Clin Res Hepatol Gastroenterol. 2014;38(2): 201-8. https://doi.org/10.1016/j.clinre.2013.11.002.

14. Nagai S, Yoshida A, Facciuto M, Moonka D, Abouljoud MS, Schwartz ME, et al. Ischemia time impacts recurrence of hepatocellular carcinoma after liver transplantation. Hepatology (Baltimore, Md). 2015;61(3):895-904.

15. Faber W, Stockmann M, Kruschke JE, Denecke T, Bahra M, Seehofer D. Implication of microscopic and macroscopic vascular invasion for liver resection in patients with hepatocellular carcinoma. Dig Surg. 2014;31(3): 204-9. https://doi.org/10.1159/000365257.

16. Jung SW, Park NH, Shin JW, Park BR, Kim CJ, Lee J-E, et al. Prognostic impact of telomere maintenance gene polymorphisms on hepatocellular carcinoma patients with chronic hepatitis B. Hepatology (Baltimore, Md). 2014;59(5):1912-20

17. Wu L, Yang Z, Zhang J, Xie H, Zhou L, Zheng S. Long noncoding RNA HOTTIP expression predicts tumor recurrence in hepatocellular carcinoma patients following liver transplantation. Hepatobiliary Surg Nutr. 2018;7(6): 429-39. https://doi.org/10.21037/hbsn.2018.10.07.

18. Hodo Y, Honda M, Tanaka A, Nomura Y, Arai K, Yamashita T, et al. Association of interleukin-28B genotype and hepatocellular carcinoma recurrence in patients with chronic hepatitis C. Clin Cancer Res. 2013;19(7): 1827-37. https://doi.org/10.1158/1078-0432.CCR-12-1641.

19. Oka R, Sasagawa T, Ninomiya I, Miwa K, Tanii H, Saijoh K. Reduction in the local expression of complement component 6 (C6) and 7 (C7) mRNAs in oesophageal carcinoma. Eur J Cancer. 2001;37(9):1158-65. https://doi.org/1 0.1016/S0959-8049(01)00089-2.

20. Ying L, Zhang F, Pan X, Chen K, Zhang N, Jin J, et al. Complement component 7 (C7), a potential tumor suppressor, is correlated with tumor progression and prognosis. Oncotarget. 2016;7(52):86536-46. https://doi. org/10.18632/oncotarget.13294.

21. Ricklin D, Hajishengallis G, Yang K, Lambris JD. Complement: a key system for immune surveillance and homeostasis. Nat Immunol. 2010;11(9):785-97. https://doi.org/10.1038/ni.1923.

22. Dutkowski P, De Rougemont O, Müllhaupt B, Clavien P-A. Current and future trends in liver transplantation in Europe. Gastroenterology. 2010; 138(3):802-9.e1-4

23. Barroso S, Sánchez B, Alvarez AJ, López-Trascasa M, Lanuza A, Luque R, et al. Complement component C7 deficiency in two Spanish families. Immunology. 2004;113(4):518-23. https://doi.org/10.1111/j.1365-2567.2004. 01997.x.

24. Afshar-Kharghan V. The role of the complement system in cancer. J Clin Invest. 2017;127(3):780-9. https://doi.org/10.1172/JC190962. 
25. Pio R, Ajona D, Lambris JD. Complement inhibition in cancer therapy. Semin Immunol. 2013;25(1):54-64. https://doi.org/10.1016/j.smim.2013.04.001.

26. Zhong L, Li H, Li Z, Shi B, Wang P, Wang C, et al. C7 genotype of the donor may predict early bacterial infection after liver transplantation. Sci Rep. 2016; 6(1):24121. https://doi.org/10.1038/srep24121.

27. Recommendations guiding physicians in biomedical research involving human subjects. World Medical Association Declaration of Helsinki. J Med Liban. 1994;42(2):88-9.

28. Chandrashekar DS, Bashel B, Balasubramanya SAH, Creighton CJ, PonceRodriguez I, Chakravarthi BVSK, et al. UALCAN: a portal for facilitating tumor subgroup gene expression and survival analyses. Neoplasia. 2017:19(8):64958. https://doi.org/10.1016/j.neo.2017.05.002.

29. Shi YY, He L. SHEsis, a powerful software platform for analyses of linkage disequilibrium, haplotype construction, and genetic association at polymorphism loci. Cell Res. 2005:15(2):97-8.

30. Qin X, Gao B. The complement system in liver diseases. Cell Mol Immunol. 2006;3(5):333-40.

\section{Publisher's Note}

Springer Nature remains neutral with regard to jurisdictional claims in published maps and institutional affiliations.

Ready to submit your research? Choose BMC and benefit from:

- fast, convenient online submission

- thorough peer review by experienced researchers in your field

- rapid publication on acceptance

- support for research data, including large and complex data types

- gold Open Access which fosters wider collaboration and increased citations

- maximum visibility for your research: over $100 \mathrm{M}$ website views per year

At BMC, research is always in progress.

Learn more biomedcentral.com/submissions 